\title{
Recession coverage with coronally advanced flap along with Prf membrane- A case report
}

\author{
Sukhmeet Kaur ${ }^{1}$, Rasveen Kaur ${ }^{2, *}$, Preetika Bansal ${ }^{3}$, Chandni Mittal ${ }^{4}$, Supreet Jhind ${ }^{5}$ \\ ${ }^{\mathbf{1 , 2 , 5}}$ Senior Lecturer, ${ }^{\mathbf{3}}$ Reader, ${ }^{\mathbf{4}}$ Junior Lecturer, Dept. of Periodontics, ${ }^{\mathbf{1 , 3}, 4}$ Dashmesh Institute of Research \& Dental Sciences, \\ Faridkot, Punajb, ${ }^{2,5}$ Maharishi Markandeshwar College of Dental Sciences \& Research, Mullana, Haryana, India
}

*Corresponding Author:

Email: dr.rasveenkaur@gmail.com

\begin{abstract}
Gingival recession is a common pesky problem affecting almost all middle and older aged to some degree and in patients with good oral hygiene as well as in periodontally untreated populations with poor oral hygiene. Gingival recession has been associated with dentinal hypersensitivity, root caries and esthetic compromise. Various periodontal plastic surgical procedures are available including coronally advanced flap (CAF), each having advantages and disadvantages. To improve the clinical outcome of such surgical procedures, several regenerative materials have been combined with it. In this case report, we aimed the root coverage in Miller's class II by means of coronally advanced flap technique along with PRF membrane. A platelet-rich fibrin (PRF) membrane is a readily available and inexpensive biomaterial that is beneficial in periodontal plastic surgery procedures.
\end{abstract}

Keywords: Gingival recession, Root coverage, Coronally advanced flap, Platelet-rich membrane.

\section{Introduction}

Gingival recession is an apical migration of the gingival margin tissue relative to the cemento-enamel junction characterized by the exposure of the root surface. Several factors influence the development of marginal tissue recession including traumatic tooth brushing technique trauma, ${ }^{1}$ plaque-induced inflammation, tooth alignment, orthodontics, restorative procedures, high muscle attachment and frenal pull. ${ }^{2}$ Isolated gingival recessions have been treated by several techniques. ${ }^{3}$ The migration of the marginal tissue in an apical direction may lead to esthetic, dentin hypersensitivity, root caries, and cervical wear recessions. Various methods for performing mucogingival grafts to cover denuded root surfaces are available. But coronally advanced flap (CAF) is a predictable surgical procedure when there is adequate keratinized tissue present apical to the recession defect in the treatment of Miller Class I and II gingival recessions. ${ }^{4} \mathrm{CAF}$ alone gives an unstable result for long-term period, despite of having many advantages. Such procedure leads to formation of long junctional epithelium, which is risk factor for future recurrence of gingival recession. To improve the results various regenerative procedures have been tried with $\mathrm{CAF}$ which enhances root coverage. One of such material is Platelet rich fibrin (PRF) which is a second generation autologous platelet concentrate and does not require any extensive preparation as in needed in the preparation of PRP. The growth factors within platelet concentrates (platelet-rich plasma [PRP] and plateletrich fibrin [PRF]) up-regulate cellular activity, effective in the enhancement of early wound healing and are promoters of periodontal tissue regeneration. ${ }^{5}$ Platelet rich fibrin (PRF) is a 3-D polymerized matrix in which platelet, cytokines, leucocytes, various growth factors including vascular endothelial growth factor (VEGF), insulin-like growth factor, platelet-derived growth factor (PDGF), transforming growth factor (TGF), epidermal growth factor, basic fibroblast growth factor and circulating stem cells are trapped and that can serve as a resorbable membrane. Due to these factors, PRF accelerates wound healing and has a supportive effect on the immune system, cell migration and proliferation. ${ }^{6,7}$ Because of various inherent factors present in autologous platelet concentrate which has the capacity for bone regeneration and accelerate soft tissue wound healing, the gingival recession shown in this case report, was treated using autologous PRF membrane combined with CAF.

\section{Case Report}

A 45 year old male patient came in the department of Periodontology at Dasmesh Intitute of Research and Dental Sciences, Faridkot with good general health complaining of sensitivity in upper tooth region. During clinical examination, Miller's class-II gingival recession noticed in relation to maxillary right canine (Fig 1). Due to the presence of sufficient attached gingiva apical to recession in the buccal area, surgical planning was directed to the coronally positioned flap along with PRF membrane in order to obtain the desirable result. 


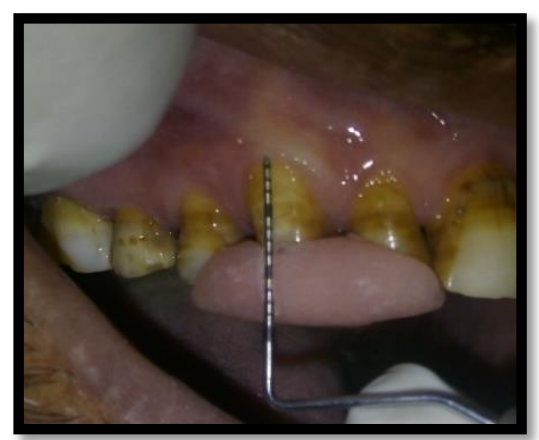

Fig. 1: Pre-Op view

\section{Presurgical therapy}

Proper medical history was taken. After that required laboratory investigations were performed and the patient received basic periodontal therapy included scaling, root planning previously to the surgery. A customized acrylic occlusal stent was fabricated with cold cure acrylic resin for further readings. Vertical groove was made on the midbuccal aspect. The caliberated UNC-15 periodontal probe was placed in the stent groove to record the Relative Attachment Level (RAL) which is measured from the lower edge of the stent to base of pocket.

\section{Platelet Rich Fibrin Preparation}

The Platelet Rich Fibrin was prepared following the protocol developed by Choukroun et al. ${ }^{8}$ Before surgery, intravenous blood was drawn from antecubital vein in 10-ml sterile tubes and immediately centrifuged in centrifugation machine at 3,000 revolutions per minute for 10 minutes. At the end of centrifugation, three layers were seen, the top layer containing supernatant serum, the fibrin clot at the middle layer, and the bottom layer containing the red blood corpuscles. With the help of sterile tweezers and scissors the fibrin clot was easily separated from the RBC base and then kept in a sterile dappen dish. Prior to use, it was slightly squeezed between the guaze pieces to remove its serum content.

\section{Surgical procedure}

Proper isolation of the surgical field was done. With the help of Gracey curettes, recession defect was thoroughly scaled. Then the operative site was anesthetized using 2\% Lignocaine with 1:80,000 adrenaline. After raising full thickness mucoperiosteal flap, two parallel vertical incisions at the line angles of the same teeth were given (Fig. 2, 3) to outline the surgical area. An intrasulcular incision was made using a no.15 scalpel blade to connect the two vertical incisions. The flap was reflected to the level of the mucogingival junction. To facilitate coronal movement, the base of the flap was undermined and separated from the periosteum with scissors. PRF membrane already prepared was positioned over the root coronal to the cemento-enamel junction and apically $2-3 \mathrm{~mm}$ beyond the bony margin (Fig. 4). The flap was then coronally positioned to cover the membrane. Sling suture was given with 4-0 nonresorbable braided silk suture to secure it coronally. Oblique releasing incisions were closed using simple interrupted sutures (Fig. 5). Gentle pressure was applied against the flap for 2-3 minutes to secure a good adaptation. A periodontal dressing was applied to protect the surgical area for 14 days (Fig. 6).

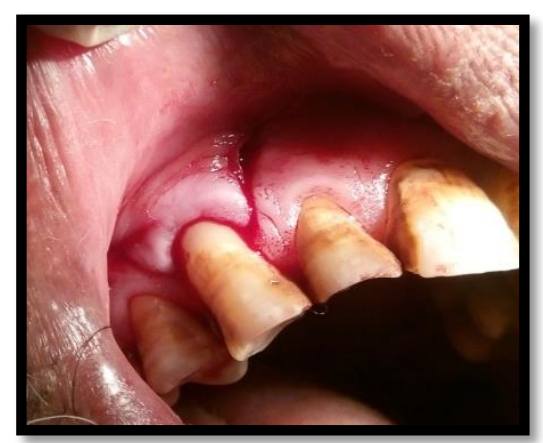

Fig. 2: Incision placed

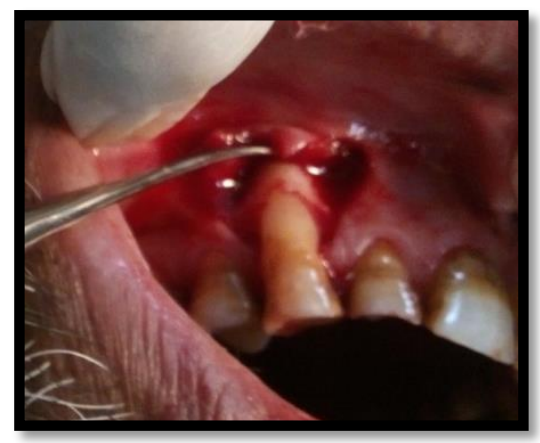

Fig. 3: Flap reflection

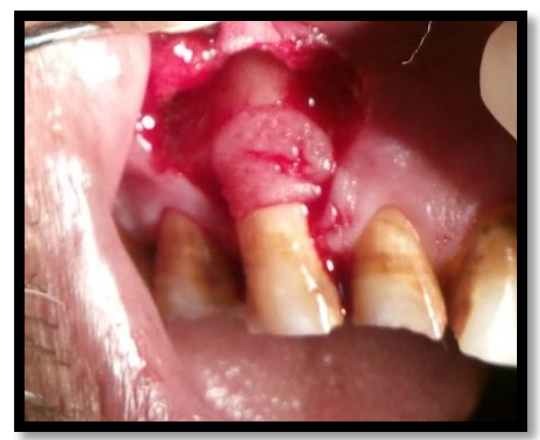

Fig. 4: PRF placement 


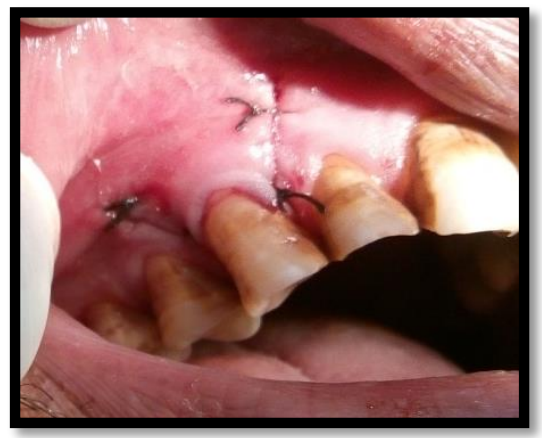

Fig. 5: Suture placed

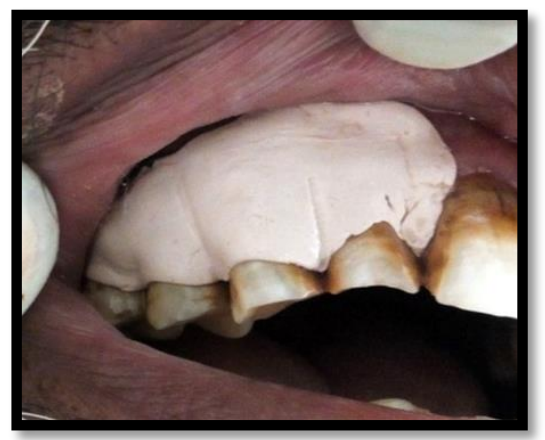

Fig. 6: COE pak placed

\section{Post Operative Care}

Patients were prescribed antibiotics amoxicillin $500 \mathrm{mg} 3$ times a day for 3 days and analgesic ibuprofen 400mg 3 times a day for 3 days. Post-operative instructions were given and patient was informed to report after 14 days for suture removal. Complete root coverage was noticed at that time (Fig. 7).

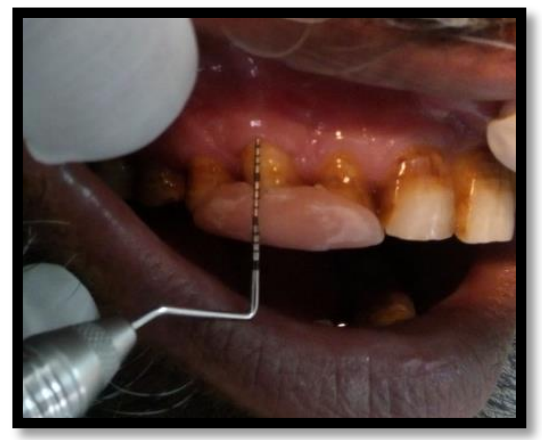

Fig. 7: Post-Op view

\section{Results}

An uneventful healing was observed at the time of suture removal. After 3 months follow up, 100\% root coverage was noted. No post-operative complication was observed. The patient did not experience any postoperative morbidity.

\section{Discussion}

Treatment of gingival recession is now a major concern due to the increasing demand for cosmetic treatment. The complete root coverage not only lead to an esthetic correction but also helps in reduction of hypersensitivity (Chambrone et al 2012). ${ }^{9}$ The present case report aimed at treating Miller's Class-II gingival recession. Such type of recession defect could be treated with pedicle soft tissue grafts, free soft tissue grafts or combinations of the two. Among the pedicle grafts, the CAF is one of the good options to cover exposed root surface. It has many advantages: no need of a separate surgical site for graft; provides a perfect color match with the surrounding tissue and the procedure does not require an extended surgical or recovery time. The result of the present case reported that the coronally advanced flap with PRF membrane was effective in treating the isolated gingival recession type defects. CAF alone can be successfully treated the sites but sometimes recurrence occurs due to formation of long junctional epithelium. CAF along with PRF showed promising results as verified by various studies. ${ }^{10-12} \mathrm{PRF}$ also promotes regeneration with more stable result. Due to presence of various growth factors, it exhibits chemotactic and mitogenic properties. The growth factors may enhance soft tissue healing and angiogenesis. Leukocytes have a strong influence on growth factor release, immune regulation, antiinfectious activities and matrix remodelling during healing. PRF membrane shows some mechanical adhesive properties so there is no need of sutures. Various factors determine treatment outcome like root prominence, tooth position, vestibular depth, high frenal pull, gingival thickness as well as tooth brushing technique. Thus proper examination of the recession site is very important for successful treatment.

\section{Conclusion}

The coronally advanced surgical technique with PRF membrane is very effective in treating isolated gingival recessions. CAF is safe and effective while treating class I and class II Miller gingival recession defects, because there is no need of second surgery for donor. There is need of histologic evaluation to find out the type of healing. Hence, the effect of PRF on the establishment of a connective tissue attachment remains to be determined.

\section{References}

1. Checchi L, Daprile G, Gatto MR, Pelliccioni GA (1999). Gingival recession and toothbrushing in an Italian School of Dentistry: a pilot study. J Clin Periodontol; 26(5):27680.

2. Trott JR, Love B (1996). An analysis of localized gingival recession in 766 Winnipeg High School students. Dent Pract Dent Rec;16(6):209-13.

3. Roccuzzo M, Bunino M, Needleman I, Sanz M (2002). Periodontal plastic surgery for treatment of localized 
gingival recessions: A systematic review. J Clin

Periodontol;29(Suppl. 3):178-94.

4. Baldi C, Pini-Prato GP, Pagliaro U, Nieri M, Saletta

D, Muzzi L, Cortellini P (1999). Coronally advanced flap procedure for root coverage. Is flap thickness a relevant predictor to achieve root coverage? A 19case series. J Periodontol;70:1077-84.

5. Del Corso M, Vervelle A, Simonpieri A, Jimbo R, Inchingolo F, Sammartino G, et al (2012). Current knowledge and perspectives for the use of platelet-rich plasma (PRP) and platelet-rich fibrin (PRF) in oral and maxillofacial surgery part 1 : Periodontal and dentoalveolar surgery. Curr Pharm Biotechnol;13:120730 .

6. Dohan Ehrenfest DM, Bielecki T, Del Corso M, Inchingolo F, Sammartino G (2010). Shedding light in the controversial terminology for platelet-rich products: Platelet-rich plasma (PRP), platelet-rich fibrin (PRF), platelet-leukocyte gel (PLG), preparation rich in growth factors (PRGF), classification and commercialism. J Biomed Mater Res A;95:1280-82.

7. Dohan Ehrenfest DM, Diss A, Odin G, Doglioli P, Hippolyte MP, Charrier JB (2009). In vitro effects of Choukroun's PRF (platelet-rich fibrin) on human gingival fibroblasts, dermal prekeratinocytes, preadipocytes, and maxillofacial osteoblasts in primary cultures. Oral Surg Oral Med Oral Pathol Oral Radiol Endod;108:341-52.

8. Choukroun J, Diss A, Simonpieri A, Girard MO, Schoeffler C, Dohan SL, et al (2006). Platelet-rich fibrin (PRF): A second-generation platelet concentrate. Part IV: Clinical effects on tissue healing. Oral Surg Oral Med Oral Pathol Oral Radiol Endod;101:e56-60.

9. Chambrone L, Pannuti CM, Tu YK, Chambrone LA (2012). 'Evidence-based periodontal plastic surgery II. A individual data meta-analysis for evaluating factors in achieving complete root coverage', J Periodontol;83:47790.

10. Thamaraiselvan M, Elavarasu S,Thangakumaran S, Gadagi JS, Thangavelu (2015). Comparative clinical evaluation of coronally advanced flap with or without platelet rich fibrin membrane in the treatment of isolated gingival recession. J Indian SocPeriodontol;19:66-71.

11. Padma R, Shilpa A, Kumar PA, Nagasri M, Kumar C, Sreedhar A, et al (2013). A split mouth randomized controlled study to evaluate the adjunctive effect of platelet-rich fibrin to coronally advanced flap in miller's Class-I and II recession defects. J Indian Soc Periodontol;17:631-6.

12. Anil kumar K, Geetha A, Umasudhakar, Ramakrishnan T, Vijayalakshmi R, Pameela E (2009). Platelet-richfibrin: A novel root coverage approach. J Indian Soc Periodontol;13:50-4. 